\title{
LA MATERNIDAD SUBROGADA: UN ASUNTO DE DERECHOS FUNDAMENTALES
}

\author{
ANA VALERO HEREDIA \\ Profesora Titular $(A)$ de Derecho Constitucional \\ Universidad de Castilla la Mancha
}

\begin{abstract}
SUMARIO
I. Introducción. II. El mal llamado «derecho» a la reproducción. III. El derecho a la autonomía de la mujer gestante: libertad contractual vs. explotación reproductiva. IV. El derecho a la dignidad e integridad física y moral de la mujer gestante. V. El interés superior del menor. VI. Conclusiones. VII. Bibliografía.
\end{abstract}

\section{INTRODUCCIÓN}

La Gran Sala del Tribunal Europeo de Derechos Humanos puso fin al asunto Paradiso y Campanelli c. Italia (25358/12), dictando una Sentencia que, sin duda, posee efectos disuasorios claros para los ciudadanos de los estados miembros del Consejo de Europa que, como Italia, no permiten la gestación por sustitución. Pues en ella, la Corte de Estrasburgo falla en contra de los padres de intención que pretendían inscribir en el Registro civil italiano la paternidad de un niño gestado «por sustitución» en Rusia. Y ello afirmando que la negativa de las autoridades italianas no produce la lesión del derecho a «la intimidad familiar» de los pretendidos padres — reconocido en el artículo 8 de la Convención - en la medida en que no se puede establecer la existencia de unos lazos familiares que deban ser protegidos por el Derecho cuando los mismos se han constituido en violación de la ley.

La maternidad subrogada o gestación por sustitución, comúnmente conocida como «vientre de alquiler», consiste en la implantación por fecundación in vitro o inseminación artificial de un embrión en una madre gestante, con la que los padres de intención han firmado un contrato previo, con o sin remuneración económica. Subrogarse implica en Derecho sustituir a otro en una situación jurídica, por lo que, en el contexto de la maternidad, subrogarse implica «sustituir en la gestación». 
Pues bien, un empleo extensivo de esta práctica ha desatado en los últimos años un acalorado debate social a nivel europeo y, muy activamente en España, debido a los problemas éticos y jurídicos que plantea. La maternidad subrogada constituye uno de los temas más controvertidos entre los muchos que afectan a la disposición del cuerpo de la mujer. Así, como sucede en otros temas relacionados con el cuerpo femenino, como el aborto o la prostitución, las posturas son contrapuestas y, llamativamente, todas ellas apelan a distintos derechos fundamentales de las partes implicadas para defender sus argumentos.

Entre los derechos invocados por quienes defienden la legalización de esta práctica se encuentran principalmente: el derecho a la reproducción de los padres de intención, siendo la maternidad subrogada un vehículo para hacer efectiva la igualdad reproductiva entre parejas fértiles e infértiles, heterosexuales y homosexuales; y la autonomía de la mujer gestante que se plasma en su libertad contractual.

En contra, sin embargo, se plantean numerosas objeciones éticas y jurídicas, que van desde la cosificación del cuerpo de la mujer, que es objeto de un contrato de alquiler para satisfacer un deseo de otros; la vulneración de la dignidad y de la integridad física y moral de las gestantes; la comercialización de los niños o la explotación de las mujeres que se encuentran en un estado de necesidad económica.

Esta diversidad de argumentos a favor o en contra de la maternidad subrogada se corresponde con la disparidad con que los Estados se posicionan con respecto a esta práctica en sus respectivos ordenamientos jurídicos y respecto de las consecuencias jurídicas para las partes implicadas, lo que conlleva una gran inseguridad jurídica.

La maternidad subrogada está permitida en algunos estados de Estados Unidos como Arkansas, California, Connecticut, Dakota del Norte, Delaware, Distrito de Columbia, Florida, Illinois, Maine, Nevada, Nuevo Hampshire, Oregón, Texas, Utah y Virginia Occidental, ya sea por ley expresa o por jurisprudencia. También, países como Rusia, India, Ucrania, Georgia, Armenia o Tailandia, permiten o han permitido hasta fechas muy recientes acudir a esta técnica a título gratuito o a cambio de contraprestación económica, que es lo más habitual. Algunos de estos países han modificado recientemente sus legislaciones ante el «efecto llamada» que el carácter benévolo de sus legislaciones estaba provocando, optando por normativas más estrictas o por la prohibición total.

Los países que han modificado su legislación en esta dirección son India — que hasta la fecha estaba a la cabeza a nivel mundial por el número de niños gestados dentro de sus fronteras-, Nepal, Camboya, Tailandia o el Estado de Tabasco en México. Estos Estados han adoptado soluciones diferentes que van desde prohibir la contratación de mujeres de su nacionalidad a los extranjeros a exigir la residencia de al menos uno de los miembros cuando los contratantes son una pareja. 
Con respecto a Rusia o Ucrania, debe tenerse en cuenta que sus legislaciones excluyen la capacidad de contratación a los homosexuales o a las personas solas.

En segundo lugar, nos encontramos con algunos países europeos como Reino Unido, Dinamarca y, recientemente Portugal, y otros como Canadá que admiten la maternidad subrogada sólo en caso de que se realice altruistamente, es decir, que la gestante no obtenga un beneficio económico ni que el proceso se desarrolle como una actividad comercial que permita el lucro.

Y finalmente, nos encontramos con un tercer grupo de países que prohíben expresamente cualquier contrato de maternidad por sustitución, tanto comercial como altruista, entre los que se encuentra España, la mayor parte de países europeos, como Austria, Italia, Alemania, Hungría, Islandia o Serbia, ciertos Estados de EEUU o Hong Kong.

La distinta regulación adoptada por los Estados ha convertido a la maternidad subrogada es un asunto global que solo puede ser correctamente abordado globalmente, pues como ha afirmado la Oficina Permanente de la Conferencia de la Haya de Derecho Internacional Privado: «en una era de globalización, donde se cruzan las fronteras con mayor frecuencia, las diferencias en las leyes nacionales de los Estados puede dar lugar a cuestiones complejas de derecho internacional privado sobre el establecimiento o reconocimiento de la filiación legal de los niños, cuestiones que afectan a sus derechos humanos» ${ }^{1}$.

Así, la prohibición de la gestación por sustitución por el ordenamiento jurídico de un determinado Estado conlleva que los ciudadanos de ese Estado acudan a otros Estados donde esta práctica se permite, dependiendo la elección que realicen de las facilidades para llevarla a cabo y el coste de la misma, que es muy variado, lo que genera «una suerte de turismo reproductivo internacional en busca del lugar más lejano o del mejor precio» ${ }^{2}$. Y ello, esperando que su Estado de pertenencia reconozca la filiación cuando se proceda a su inscripción civil en aras de la protección del interés del menor, algo que abordaremos con mayor detenimiento en próximos epígrafes.

Ahora cabe destacar que en dicho mercado es especialmente relevante el papel de las agencias intermediarias que, aun ubicadas en los Estados que no reconocen estos contratos, ofrecen sus servicios libremente sin ningún tipo de control por parte de las autoridades, siendo España uno de ellos ${ }^{3}$.

1 En dichos términos se pronuncia la Oficina Permanente de la Conferencia de la Haya de Derecho Internacional Privado en su Informe de 2016: «The private international law issues surrounding the status of children, including issues arising from international surrogacy arrangements»: https://assets.hcch.net/docs/ f92c95b5-4364-4461-bb04-2382e3c0d50d.pdf

2 Nelson E., «Global Trade and Assisted Reproductive Technologies: Regulatory Challenges in International Surrogacy», The Journal of Law, Medicine and Ethics, Vol. 41, 2013.

3 Basta con teclear vientres de alquiler en google y aparecen Agencias que ofrecen la realización de este tipo de contratos desde España en: Rusia, Ucrania, Grecia, Estados Unidos, Georgia, Karzajistan, México, India, Nepal o Canadá — donde llamativamente esta solo es legal de forma altruista—: Véase, entre otras: 
Pero el telón de Aquiles de esta materia radica en que la situación de «alegalidad» en que se encuentra en la mayoría de países europeos, que no prohíben expresamente la maternidad subrogada sino que declaran la «nulidad» del contrato a posteriori $-\mathrm{y}$, siempre condicionado al interés superior del menor en cada caso- - ha abierto la puerta a un creciente «turismo reproductivo» que está generando importantes dificultades jurídicas.

En las webs de estas agencias, que proliferan a gran rapidez, pueden verse gran cantidad de tarifas, que van desde los 120.000 euros si la subrogación se lleva a cabo Estados Unidos, a los 40.000 si se realiza en Ucrania, Georgia, México, Tailandia, Karzajistan, India o Nepal, pasando por los 80.000 de Rusia o Grecia. Pero, quizás, lo más llamativo es que estas agencias ofrecen sus servicios - previa contraprestación económica - incluso en países como Canadá, cuya legislación sólo permite la maternidad subrogada en supuestos altruistas — por el módico precio de entre 80 y 90.000 euros, eso sí, indicándose en el apartado de «desventajas» que la legislación es muy restrictiva, lo que no permite la negociación económica directa con la gestante ${ }^{4}$.

Además, el contrato que firman los padres intencionales no es directamente con la madre gestante, sino con la agencia intermediaria, con lo que las cláusulas a las que aquella queda sujeta permanecen en el mayor oscurantismo.

Es por tanto evidente que dicha situación de «alegalidad» se convierte «de facto» en la principal baza del mercado libre en la materia.

La gestación por sustitución es, desde nuestro punto de vista, principalmente, un asunto de derechos fundamentales en el que se ven implicados el derecho a la vida, la integridad física y moral, la autonomía, la dignidad y el libre desarrollo de la personalidad de la madre gestante o el interés del menor. El presente estudio pretende, a través del análisis de la jurisprudencia existente, detectar los derechos de todos los sujetos implicados y extraer parámetros de ponderación que garanticen la protección de aquellos que deben priorizarse. Y ello con el fin de orientar la resolución de futuros casos y en el diseño de políticas en materia.

\section{EL MAL LLAMADO «DERECHO» A LA REPRODUCCIÓN}

El estudio de la maternidad subrogada desde la perspectiva de los derechos fundamentales implicados obliga a plantearse, en primer lugar, si existe o no un auténtico «derecho a la reproducción». O dicho en otros términos, si la paternidad o la maternidad, más allá de una opción y de un proyecto de vida, es un auténtico derecho que los poderes públicos están obligados a garantizar.

http://gestlifesurrogacy.com/programas/; http://interfertility.es/gestacion-subrogada-servicios/ (consultado el 6 de febrero de 2018).

4 https://interfertility.es/gestacion-subrogada-comparativa-paises/ (consultado el 6 de febrero de 2018). 
Quienes defienden la legitimidad de la gestación subrogada, apelan a la existencia de un llamado «derecho a procrear» o «libertad reproductiva» unido al derecho a la salud en este ámbito, en la medida en que la gestación subrogada permite hacer efectivo el derecho a tener hijos de las parejas infértiles ${ }^{5}$, pues los avances en las técnicas de reproducción asistida así lo permiten. Desde esta perspectiva, la maternidad por sustitución es vista como una técnica más que la ciencia ofrece para hacer efectivo este derecho. En el marco de dicho razonamiento, se alega incluso el principio de igualdad y no discriminación reproductiva para defender el derecho de una pareja de hombres homosexuales a tener un hijo genéticamente propio.

Es cierto que el TEDH ha reconocido la existencia de un derecho a la reproducción, enmarcado en el derecho a la intimidad personal y familiar del artículo 8 del Convenio, que engloba el derecho a emplear las técnicas de reproducción asistida. Así, en el caso Dickson contra Reino Unido, de 4 de diciembre de 2007, la Gran Sala afirmó que el artículo 8 no sólo incluye obligaciones negativas o de no injerencia para el Estado, sino que también puede incluir obligaciones positivas para éste, esto es, el deber de adoptar las medidas oportunas para que el derecho a la reproducción pueda hacerse efectivo, entre las que se encuentra el permitir el acceso a técnicas que permitan engendrar un hijo - apartado 70- Y en el caso S.H. y otros contra Austria, de 3 de noviembre de 2001, sostuvo que el uso de la procreación asistida médicamente con la intención de concebir un hijo forma parte del artículo 8 del Convenio «ya que esta elección es claramente una expresión de la vida privada y familiar» — apartado $60{ }^{6}$.

Sin embargo, debe quedar claro que la maternidad subrogada no es una técnica de reproducción asistida en sí misma, sino que es una práctica que requiere de la reproducción asistida para su efectividad y que no involucra al propio cuerpo sino el de «una tercera» que debe aceptar las consecuencias que puede conllevar someterlo a dicho proceso. Si, por el contrario, decidiéramos considerar la gestación por sustitución como una técnica de reproducción asistida más, estaríamos reduciendo a la mujer gestante a un instrumento necesario para la práctica, lo cual es un ataque directo a su dignidad como persona. La instrumentalización de la mujer y de su capacidad reproductiva para satisfacer el deseo de terceros, reduce su condición de madre al de mera "portadora», término que suelen emplear, precisamente, los contratos de subrogación.

5 FARNós AmORós, E., «El derecho a procrear debe vincularse al derecho a una salud reproductiva. Es decir, la imposibilidad de concebir es entendida como una especie de enfermedad, que queda cubierta por este derecho dando lugar a la prevención y el tratamiento apropiado de la infertilidad, así como a la libertad de decidir si se quiere tener hijos, cuándo, y con qué frecuencia»: «La reproducción asistida ante el Tribunal Europeo de Derechos Humanos»: De Evans c. Reino Unido a Parrillo c. Italia», Revista Bioética y Derecho, n. ${ }^{\circ} 36$, 2016.

6 Molero Martín-Salas, P., «La reproducción asistida en Europa: La labor armonizadora del Tribunal Europeo de Derechos Humanos», Estudios Constitucionales, n. ${ }^{\circ}$ 2, 2016. 
En este sentido es especialmente importante y reveladora la doctrina del TEDH en su recientísima Sentencia en el caso Paradiso y Campanelli contra Italia, de 24 de enero de 2017, en la que la Gran Sala revocó el fallo de la Sala en su sentencia anterior de 2015. Sin perjuicio de dejar para más adelante el estudio pormenorizado del caso, baste por el momento señalar que en ella la Corte europea señala expresamente que no existe un derecho a la maternidad/paternidad en virtud de la mera voluntad, o de la proyección de la autonomía y del desarrollo personal, plasmada en la existencia de un «proyecto paternal» ${ }^{7}$. En consecuencia, el reconocimiento de este último como título suficiente para inscribir a los hijos habidos a resultas de la firma de contratos de gestación por sustitución, no es vinculante para ningún Estado del Consejo de Europa.

Por lo que, aunque es indudable que la libertad de procreación forma parte del libre desarrollo personal, esto no debe confundirse con la existencia de un derecho a la reproducción que incluya como instrumento para hacerlo efectivo la gestación por sustitución, en la medida en que ésta implica que la madre gestante se limite a aceptar, mediante el recurso a una relación contractual de carácter mercantil, las condiciones de un contrato de gestación para otros, que es distinto a decidir ejercer, en su ámbito de libertad individual, un derecho a procrear.

Dicho en otros términos, el derecho a la maternidad implica la libertad de procrear o de adoptar. El derecho a procrear protege, a su vez, la decisión de concebir, gestar y parir un hijo, pero no reconoce en su ámbito de protección el derecho a «encargarlo» por parte de los padres intencionales, ni gestarlo para terceros.

\section{EL DERECHO A LA AUTONOMÍA DE LA MUJER GESTANTE: LIBERTAD CONTRACTUAL VS. EXPLOTACIÓN REPRODUCTIVA}

El segundo de los derechos a los que apelan los defensores de la maternidad subrogada para defender su legitimidad es el de la autonomía de la mujer gestante. Mantienen que la mujer acepta la subrogación de manera consciente y presta su consentimiento voluntariamente ${ }^{8}$.

7 «The Convention does not recognise a right to become a parent» (párrafo 215).

8 Martín Camacho, J., «La maternidad sustituta es una práctica basada en la decisión libre de adultos que ejercen sus derechos y prerrogativas, sin perjudicarse ni perjudicar a terceros, razón por la cual no puede señalarse ni objetarse a las personas que la ejercen, ni a la práctica en sí misma. Todos los participantes y personas involucradas se suelen beneficiar de la misma: el niño que nace de dicho acuerdo no hubiera nacido si la práctica no se hubiera realizado y encuentra una familia que lo recibe con mucho amor y que lo deseó profundamente, los padres logran acceder a la paternidad y tienen la posibilidad de dar amor y brindarle todos los cuidados necesarios a su hijo y por último la mujer portadora puede satisfacer sus deseos de ayudar a otras personas y obtener un beneficio, en general económico a cambio de esa ayuda»; «Maternidad subrogada: una práctica moralmente aceptable. Análisis crítico de las argumentaciones de sus detractores», http://www.fundacionforo.com.ar/pdfs/maternidadsubrogada.pdf, 2009. 
Estas posturas afirman que prohibir la maternidad subrogada supone una restricción de la libertad de la mujer para decidir sobre el ejercicio de su capacidad para gestar para terceros, disminuyendo así su autonomía para tomar sus propias decisiones (SHAPIRO, 2014).

Las citadas tesis pueden ser rebatidas, sin embargo, con los siguientes argumentos:

En primer lugar, cabe señalar que la función reproductora de una mujer es algo extra comercium, y, en consecuencia, no puede someterse a la lógica contractual. Como sostiene la doctrina «los contratos de maternidad de alquiler tienen por objeto, por una parte, las funciones reproductivas de la mujer portadora y, por otra parte, su cualidad de madre, o sea elementos que pertenecen al propio ser de una persona. Por eso están fuera del comercio, como el cuerpo humano en su conjunto, porque pertenecen al ámbito de la persona y no al de las cosas. Declarar válidos los contratos de madre portadora supondría, indirectamente, considerar al ser humano como una cosa, puesto que sólo las cosas que están en el comercio pueden ser objeto de contrato»? .

La maternidad subrogada, en consecuencia, implica la despersonalización de la madre gestante en la medida en que se produce una instrumentalización de su cuerpo para satisfacer el deseo reproductivo de otros. Estamos, por tanto, ante una forma de mercantilización de la función reproductiva ${ }^{10}$.

En segundo lugar, un dato imprescindible a tener en cuenta a efectos de entender la problemática del alquiler de la capacidad reproductiva de otra persona para acceder a la maternidad/paternidad, es el hecho de que, incluso en los países donde esta práctica es legal, sus ciudadanos realizan el proceso mayoritariamente en países en vías de desarrollo donde las condiciones son más laxas y las tarifas mucho más reducidas, lo que genera un auténtico «turismo reproductivo». En este sentido es significativo el caso de Reino Unido, donde se da la paradoja de que, a pesar de permitir la subrogación altruista, es el país europeo que se encuentra a la cabeza en la contratación de mujeres para dicho fin en el extranjero, principalmente en India, Tailandia y, en menor medida en Estados Unidos ${ }^{11}$.

Este hecho evidencia que la «maternidad altruista» es un mito que legitima y encubre el auténtico negocio a nivel mundial — principalmente para los agentes intermediarios - que supone la comercialización del cuerpo de mujeres en clara situación de necesidad económica y social.

En este sentido es especialmente esclarecedor el Informe elaborado en 2012 por el Centre for Social Research de India, bajo el título «Surrogate Motherhood.

9 Montero, E., «La maternidad de alquiler frente a la summa divisio iuris entre las personas y las cosas», Persona y Derecho, 72, 2015.

10 Aparisi Miralles, A., «Maternidad subrogada y dignidad de la mujer», Cuadernos de bioética, Vol. 28, n. ${ }^{\circ} 93,2017$.

11 bttps://www.theguardian.com/lifeandstyle/2015/mar/14/childless-britons-increasingly-surrogate-babies. 
Ethical or Commercial» ${ }^{12}$. En él se indica que: las madres gestantes carecían mayormente de formación, por lo que quedaban al albur de lo que las clínicas o agencias que las contrataba les dijera acerca de los riesgos del proceso y que, la práctica totalidad de las cien madres subrogadas entrevistadas, declararon haberlo hecho por su situación de pobreza.

Esta realidad evidencia que cabe cuestionar profundamente la autonomía de la madre gestante como derecho en el que anclar las demandas de legitimidad de la maternidad subrogada, ya que, cabe plantearse si la libertad de decisión de la gran mayoría de mujeres firmantes de este tipo de contratos, que se encuentran en una situación de especial vulnerabilidad socio-económica, no se ve viciada por dichas circunstancias vitales. Estaríamos, por tanto, en presencia de una auténtica explotación reproductiva.

Es en dicho sentido precisamente en el que se pronuncia el Tribunal Supremo español en el caso que hasta la fecha puede considerarse como case law en materia de maternidad subrogada en España, la sentencia de 6 de febrero de $2014^{13}$. En ella se enjuiciaba la pretensión de un matrimonio formado por dos varones españoles de que se inscribiese en el Registro Civil Consular español de Los Ángeles (California) el nacimiento de dos niños gemelos por medio de maternidad subrogada. La filiación de los menores había sido determinada a su favor por sentencia de un tribunal californiano de conformidad con su Código Civil de Familia. El matrimonio pretendía que se reconociera dicha filiación en España, pero el Registro Consular español denegó la inscripción acogiéndose a la nulidad del contrato de gestación por sustitución en España previsto por el artículo 10 de la Ley 14/2006, de 26 de mato, de Técnicas de Reproducción Humana Asistida, de según el cual:

«1. Será nulo de pleno derecho el contrato por el que se convenga la gestación, con o sin precio, a cargo de una mujer que renuncia a la filiación materna a favor del contratante o de un tercero.

2. La filiación de los hijos nacidos por gestación de sustitución será determinada por el parto.

3. Queda a salvo la posible acción de reclamación de la paternidad respecto del padre biológico, conforme a las reglas generales».

La pareja recurrió la decisión consular ante la Dirección General de los Registros y del Notariado, máximo órgano administrativo dependiente del Ministerio de Justicia en materia de filiaciones, que les dio la razón. Sin embargo, el Ministerio Fiscal recurrió esa decisión de la Dirección General, y tanto el Juez de Primera Instancia como la Audiencia Provincial rechazaron la inscripción de los

12 bttp://www.csrindia.org/about-us/publications/research-studies

13 https:/presnolinera.files.wordpress.com/2014/02/sentencia-del-tribunal-supremo-de-6-de-febrero-de-2014sobre-maternidad-subrogada.pdf 
niños como hijos de los dos varones que encargaron la gestación. Por último, el caso llegó ante el Tribunal Supremo que, mediante sentencia, rechazó definitivamente tal inscripción. Cabe señalar, además, que la pareja recurrió en amparo ante el Tribunal Constitucional, el cual inadmitió el recurso mediante Auto de mayo de 2016.

En esta importante sentencia, el Tribunal Supremo español afirmó que inscribir el nacimiento de los gemelos en el Registro Civil infringía el orden público internacional español, en el que se incluyen valores tan importantes como la autonomía y la dignidad de la madre gestante y el respeto a su integridad física y moral.

Los pretendidos padres aspiraban a que se reconociera a su favor la paternidad de los menores en virtud del interés superior de estos que en caso contrario se verían, según su criterio, en una situación de desprotección. Sin embargo, el Tribunal Supremo afirmó que la satisfacción del interés superior de los menores no es un principio que pueda conseguirse infringiendo la ley pues ésta protege otros bienes jurídicos fundamentales que también resultan involucrados como el del respeto a la dignidad y la integridad moral de la mujer gestante, el de evitar la explotación del estado de necesidad en que pueden encontrarse mujeres pobres, o el de impedir la mercantilización de la gestación y la filiación.

Así, afirmó literalmente que nuestro Derecho: «no acepta que los avances en las técnicas de reproducción humana asistida vulneren la dignidad de la mujer gestante y del niño, mercantilizando la gestación y la filiación, cosificando a la mujer gestante y al niño, permitiendo a determinados intermediarios realizar negocio con ellos, posibilitando la explotación del estado de necesidad en que se encuentran mujeres jóvenes en situación de pobreza y creando una especie de ciudadanía censitaria en la que solo quienes disponen de elevados recursos económicos pueden establecer relaciones paterno filiales vedadas a la mayoría de la población».

Y señaló, como medidas alternativas para evitar la desprotección de los menores, la posibilidad de que reclamase la paternidad aquel miembro de la pareja que había aportado sus genes al embarazo y, para el caso de que ninguno de ellos fuese padre biológico, la opción del acogimiento familiar o la adopción.

Esta doctrina del Tribunal Supremo español ha sido recientemente avalada por el TEDH en la citada Sentencia de 24 de enero de 2017, en el caso Paradiso y Campanelli contra Italia ${ }^{14}$. Se trataba de un matrimonio italiano que contrató una maternidad subrogada en Rusia y, tras el nacimiento, el bebé fue inscrito como hijo de ambos en aquel país. Al regresar a Italia con el niño las autoridades italianas se negaron a realizar la inscripción de la filiación a favor del matrimonio debido a la nulidad de este tipo de contratos en Italia, y el niño fue dado en adopción a otra familia. 
La Gran Sala del TEDH ha dicho a este respecto que «no se puede establecer la existencia de unos lazos familiares que deban ser protegidos por el Derecho cuando esos lazos se han constituido en violación de la ley», como en este caso. Además, ha señalado algo muy importante a efectos de interpretar correctamente el pretendido «derecho a la reproducción» en el que se basan la mayor parte de los defensores de la maternidad subrogada: «no existe un deber del Estado de proteger el mero «deseo» de constituir una familia, con independencia de la forma en la que este propósito se lleve a cabo. No existe un derecho a la materni$\mathrm{dad} /$ paternidad basado en la mera voluntad o en la proyección de la autonomía y del desarrollo personal».

En los votos concurrentes de algunos de los Magistrados de la Corte se afirma expresamente que la maternidad subrogada «sea remunerada o no constituye un trato degradante tanto para la gestante como para el niño, pues implica una drástica ruptura del vínculo único que se crea entre ellos, ya que la medicina moderna ha proporcionado evidencias que demuestran el impacto determinante del periodo prenatal para el posterior desarrollo del ser humano». Con el añadido, sostienen los jueces, de que «la maternidad subrogada, en todas sus modalidades, es contraria a la dignidad humana porque trata a la gestante y al niño como medios al servicio del cumplimiento de los deseos de los contratantes, y no como fines en sí mismos».

Otro voto concurrente, el del juez Dedov, es especialmente interesante en la medida en que aborda el problema de la maternidad subrogada desde una perspectiva global. Según su parecer, «dicha cuestión está estrechamente ligada a un problema global de discriminación social y de desigualdad pues tiene lugar mayoritariamente en países pobres, empleando como gestantes a mujeres pobres. Por eso, se trata de un problema que conlleva un gran desafío para las naciones europeas, pues implica optar entre permitir o no que el cuerpo humano se convierta en un producto de mercado; entre permitir o no que mujeres vulnerables y sin formación opten por la explotación de sus cuerpos; y escoger entre crear una sociedad dividida entre naciones desarrolladas y naciones en vías de desarrollo».

Así pues, cabe afirmar con la doctrina que «si la subrogación se convierte para la madre subrogante en una opción laboral y una oportunidad para lograr una estabilidad económica para ellas y sus familias, la libertad reproductiva pensada como un derecho a la autodeterminación es nula. En tanto las mujeres deban ofrecer sus cuerpos y su útero, y sean empujadas a convertirse en «fabricantes de bebés» para paliar sus necesidades básicas, la libertad reproductiva estará viciada desde sus inicios, al margen de que de esta forma estamos avalando la creación de un mercado» ${ }^{15}$.

15 Mir CANDAL, L., «La maternidad intervenida: reflexiones en torno a la maternidad subrogada», Revista RedBioética/UNESCO, Montevideo, UNESCO Office Montevideo, 2010. 


\section{EL DERECHO A LA DIGNIDAD Y A LA INTEGRIDAD FÍSICA Y MORAL DE LA MUJER GESTANTE}

A todos los argumentos esgrimidos hasta ahora cabe añadir que la realidad de la maternidad subrogada en el mundo evidencia que esta práctica atenta contra la dignidad y la integridad física y moral de la mujer gestante.

Como es sabido, la dignidad «tiene como sujeto a la persona humana, tanto en su dimensión corporal, como en su dimensión racional, que aseguran su sociabilidad, responsabilidad y trascendencia» ${ }^{16}$. De acuerdo con la concepción Kantiana de la dignidad humana, ésta se halla vinculada a la idea de que sólo el ser humano, el ser racional, existe como fin en sí mismo y posee un valor absoluto en virtud de esa autonomía. Esta doctrina, adoptada en la segunda mitad del siglo Xx por numerosos juristas y tribunales constitucionales, se utiliza hoy en Derecho con el nombre de fórmula del objeto (Objektformel) o «formula de no instrumentalización» del ser humano: el hombre, como fin en sí mismo, tiene una dignidad que no puede ser vulnerada por nadie ${ }^{17}$.

En palabras de Kant: «la humanidad misma es la dignidad, porque el hombre no puede ser tratado por ningún hombre (ni por otro, ni siquiera por sí mismo) como un simple medio, sino siempre, a la vez, como un fin, y en ello precisamente estriba su dignidad (la personalidad)» ${ }^{18}$.

La dignidad está íntimamente vinculada a los derechos fundamentales, en tanto razón de ser, fin y límite de los mismos. Por lo que, mientras que los objetos pueden emplearse como medios al servicio de determinados fines, la persona, de acuerdo con su dignidad, debe ser considerada y tratada como un fin en sí misma. De ello se deriva que la persona, incluidos el cuerpo humano y sus funciones, no puede instrumentalizarse para alcanzar fines que le son ajenos ni, en consecuencia, puede ser objeto de transacción.

Por lo que, frente a los argumentos que defienden la maternidad subrogada basándose en la autonomía de la mujer gestante ${ }^{19}$, cabe oponer que dicha autonomía no puede amparar conductas que sean contrarias a las demandas de la dignidad de la persona que, por esencia, es irrenunciable. En la medida en que la gestación por sustitución implica el empleo de los órganos reproductivos para satisfacer fines ajenos, la misma es claramente contraria a la dignidad humana en

16 Alegre Martínez, M. A., La dignidad de la persona, como fundamento del ordenamiento constitucional español, Universidad de León, 1996.

17 García Cuadrado, A.M., «Problemas constitucionales de la dignidad humana», Persona y Derecho, Vol. 67, 2012.

18 Kant, I., Metafísica de las costumbres, Tecnos, 2005.

19 Presno Linera, M. A. y Jiménez Blanco, P., «Libertad, igualdad, ¿maternidad? La gestación por sustitución y su tratamiento en la jurisprudencia española y europea», $R E D E$, n. ${ }^{\circ}$ 51, 2014: https://presnolinera.files. wordpress.com/2014/12/libertad-igualdad-maternidad-gestacic3b3n-por-sustitucic 3 b3n-revista-espac3b1ola-de-derecho-europeo-nc2ba-51.pdf 
tanto en cuanto despoja de todo valor a la dimensión personal de la madre gestante y al propio proceso de concepción.

Por lo que respecta al derecho a la integridad física y moral, el llamado Informe Wendel, del Comité de Bioética de España, «sobre aspectos éticos y jurídicos de la maternidad subrogada», de 19 de mayo de $2017^{20}$, señala que es común que las agencias que median en este tipo de contratos intenten atraer la demanda ofreciendo una amplia gama de posibilidades de elección para los contratantes relacionadas con las características de la gestante, el seguimiento del embarazo, la modalidad de parto y, por supuesto, las características del niño. Así, en las páginas web de estas empresas se garantiza la posibilidad de elegir donantes de óvulos caucásicas, cuyas características fenotípicas podrán ser conocidas mediante fotografías; la posibilidad de elegir el sexo del niño; o se les atribuye la decisión acerca del número de embriones (entre uno y tres) que se implantará a la gestante.

Además, cada vez que se realiza una implantación es necesario someter a la gestante a la estimulación hormonal con consecuencias negativas para su salud. Y, lógicamente, las tasas de éxito de estas mujeres dan lugar a una «selección natural» entre ellas: las que consiguen mejores tasas de implantación estarán más cotizadas mientras que las que resulten menos «productivas» tenderán a quedar al margen del mercado.

Las agencias garantizan que los contratantes conozcan la evolución médica del embarazo e incluso que acudan a los controles médicos de la embarazada; se asegura que la gestante será una mujer joven, en buen estado de salud y psicológicamente preparada para no generar vínculos afectivos con el niño que gestará; y, lo habitual es que en el parto se emplee la cesárea porque de este modo el niño corre menos riesgos y reduce las posibilidades de que la gestante cree vínculos afectivos con él.

Por otro lado, la posibilidad de que los contratantes mantengan contacto con la gestante tras el parto se deja en manos de aquellos, que deciden unilateralmente si quieren mantenerlo o prefieren ocultar los orígenes de la gestación al niño. A ello se añade que lo habitual es que los solicitantes de este tipo de contratos sean los que decidan cuántos embriones se transfieren y suelen optar como mínimo por dos lo cual, desde un punto de vista clínico, está considerado un embrazo de riesgo.

Así las cosas, es evidente que la maternidad subrogada afecta a la integridad física y psicológica de la gestante. Y ello porque quien dispone realmente de su cuerpo no es ella misma sino los solicitantes en tanto en cuanto en este tipo de contratos ellos tienen todas las facultades a su favor en orden a supervisar la óptima gestación y alumbramiento.

20 bttp://assets.comitedebioetica.es/files/documentacion/es/informe_comite_bioetica_aspectos_eticos_juridicos_ maternidad_subrogada.002.pdf 
En el año 2015, la Unión Europea publicó su Informe anual sobre Derechos Humanos y Democracia en el Mundo (2014), en el que encontramos una condena explícita de la subrogación, cuya prohibición se recomienda. Así, dentro del apartado a los derechos de las mujeres y de las niñas, en su parágrafo 115, el texto «condena la práctica de la gestación por sustitución, que es contraria a la dignidad humana de la mujer, ya que su cuerpo y sus funciones reproductivas se utilizan como una materia prima; estima que debe prohibirse esta práctica, que implica la explotación de las funciones reproductivas y la utilización del cuerpo con fines financieros o de otro tipo, en particular en el caso de las mujeres vulnerables en los países en desarrollo, y pide que se examine con carácter de urgencia en el marco de los instrumentos de derechos humanos ${ }^{21}$.

\section{MATERNIDAD SUBROGADA E INTERÉS SUPERIOR DEL MENOR}

\section{La maternidad subrogada en España, un auténtico fraude de ley bajo la excusa de la protección del «interior superior del menor»}

A la ecuación de la maternidad subrogada cabe añadir un último factor a tener en cuenta en la ponderación de derechos que esta práctica plantea: el interés superior de los menores nacidos bajo el paraguas de este tipo de contratos. Es este interés al que se apela cuando se solicita la inscripción de su filiación en los registros civiles de los países de los que son originarios los padres intencionales. Países, en la mayoría de los cuales, esta práctica está expresamente prohibida o no se le reconoce efectos jurídicos.

España es un ejemplo claro de lo señalado. Como indicábamos al inicio del presente estudio, en nuestro país, como en la mayor parte de los Estados europeos, la maternidad subrogada no está jurídicamente permitida porque contradice su orden público, de modo que los contratos celebrados para dicho fin son nulos de pleno Derecho según lo dispuesto por el artículo 10 de la Ley de Técnicas de Reproducción Humana Asistida, de 2006. Sin embargo, la realidad demuestra que la realización de este tipo de contratos en el extranjero se lleva a cabo por ciudadanos españoles de una manera creciente. Y ello porque las autoridades registrales españolas proceden, a pesar de la expresa prohibición de la ley, a la inscripción de la filiación en aras de, argumentan, proteger el interés superior de los menores.

Así, la Dirección General de Registros y Notariado del Ministerio de Justicia —que es el órgano a quien corresponde fijar las directrices de actuación de los

21 Resolución del Parlamento Europeo, de 17 de diciembre de 2015, sobre el Informe anual sobre los derechos humanos y la democracia en el mundo (2014) y la política de la Unión Europea al respecto (2015/2229(INI)): http://www.europarl.europa.eu/sides/getDoc.do?pubRef=//EP//NONSGML+TA+P8-TA-2015$0470+O+D O C+P D F+V O / / E S>$ 
Registros civiles y consulares españoles— dictó en el año 2010 una Instrucción sobre «régimen registral de la filiación de los nacidos mediante gestación por sustitución», de 5 de octubre de $2010^{22}$.

En ella se establece que la plena protección jurídica el interés superior del menor requiere de la continuidad transfronteriza de una relación de filiación declarada por un tribunal extranjero, siempre que tal resolución sea reconocida en España. La Instrucción permite, por tanto, contradiciendo la legislación vigente, que en aras del interés superior del menor, se proceda a la inscripción en el Registro Civil español de la filiación de los nacidos mediante gestación por sustitución en los países donde ésta sea legal siempre que se cumplan los siguientes requisitos: presentar ante las autoridades españolas una sentencia o resolución judicial extranjera que acredite dicha filiación y que se compruebe que la mujer gestante renunció, mediante su libre consentimiento, a su patria potestad, y que quede claro que el menor no había sido objeto de comercio.

La Dirección General de Registros y Notariado considera que esta Instrucción sigue estando vigente en el ordenamiento jurídico español a día de hoy, y que a ella deben acogerse los encargados de los Registros civiles y consulares para proceder a la inscripción de los niños nacidos por contrato de maternidad subrogada. Lo que significa que, como regla general, los Registros españoles están procediendo a la inscripción de niños nacidos en el extranjero por contratos de maternidad subrogada. Y ello contradiciendo la doctrina del Tribunal Supremo español y la más reciente del TEDH.

Así, por lo que respecta al primero, en la citada Sentencia de 6 de febrero de 2014, el máximo órgano judicial español señaló que la concreción de la cláusula general del interés superior del menor debe hacerse tomando en consideración los valores asumidos por la sociedad como propios, contenidos tanto en las reglas legales como en los principios que inspiran la legislación nacional y las convenciones internacionales. Asimismo, la aplicación de este principio ha de hacerse para interpretar y aplicar la ley y colmar sus lagunas, pero no para contrariar lo expresamente previsto en la misma.

Y a esto añade que, en la ponderación de los derechos concurrentes en los supuestos de maternidad subrogada, el principio del interés del menor no es el único que se ha de tomar en consideración, pues cabe tener en cuenta, a su vez, el respeto a la dignidad e integridad moral de la mujer gestante, evitar la explotación

22 BOE, de 7 de julio de 2010. Para algunos autores esa normativa es nula por infringir flagrantemente el principio de jerarquía normativa del ordenamiento jurídico español, en cuanto que, el Ministerio de Justicia, a través de la Dirección General de los Registros y del Notariado, ha optado erróneamente por considerar que las normas reglamentarias pueden emplearse arbitrariamente en contra del Derecho vigente, vulnerando gravemente el sistema de fuentes constitucionalmente establecido y garantizado, pues el art. 9.3 de la norma suprema establece que la «Constitución garantiza [...] la jerarquía normativa»; como ya hacía el art. 1.2 CC: «Carecerán de validez las disposiciones que contradigan otra de rango superior». Véase Vela SÁNCHEZ; Maternidad subrogada: estudio ante un reto normativo, Comares, 2012. 
del estado de necesidad en que pueden encontrarse mujeres jóvenes en situación de pobreza, o impedir la mercantilización de la gestación y de la filiación.

El Tribunal Supremo reconoce que el no reconocimiento de la filiación establecida por la inscripción registral extranjera puede suponer un perjuicio para la posición jurídica de los menores pero, acto seguido, señala que el establecimiento de una filiación que contradiga los criterios previstos en la ley para su determinación, supone también un perjuicio para aquellos. Y señala, como alternativa, que la propia Ley de Técnicas de Reproducción Asistida española concede acción al progenitor biológico para reclamar la filiación, aun nacida de un contrato nulo de gestación por sustitución. De este modo, dicho progenitor tiene un instrumento adecuado para lograr la determinación de la filiación jurídica respecto del hijo así concebido y nacido. Filiación que, evidentemente, una vez determinada, podrá inscribirse en nuestro Registro Civil. Y, en el caso del otro padre o madre intencional, deberá acudir a la institución jurídica de la adopción, convirtiéndose en padre/madre adoptivos sin requerir siquiera la propuesta de la entidad pública competente, esto es, sin necesidad de que medie declaración de idoneidad del adoptante.

La incompatibilidad entre lo dispuesto por la Instrucción de la Dirección General de Registros y Notariado del año 2010 y la citada doctrina del Tribunal Supremo es clara. Por lo que, el hecho de que la Dirección General del Ministerio de Justicia siga considerando vigente y aplicable tal Instrucción, posibilitando con ello la inscripción registral en España de la filiación derivada de un contrato de gestación por sustitución celebrado en el extranjero, constituye un auténtico fraude de ley y una clara vulneración del sistema de fuentes, pues implica el reconocimiento por vía reglamentaria de una práctica legalmente inadmitida ${ }^{23}$.

\section{El «interés superior del menor» en la jurisprudencia del Tribunal Europeo de Derechos Humanos}

Como se señalaba con anterioridad, la disparidad de regulaciones en materia de maternidad subrogada ha generado innumerables problemas en relación con la inscripción registral de la filiación de los niños nacidos bajo este tipo de contratos. No es casual, por tanto, que los casos que han llegado hasta el TEDH tengan su origen en este tipo de conflictos.

23 La Dirección General de Registros y del Notariado emitió un informe, de fecha 11 de julio de 2014, en relación al régimen registral de la filiación de los nacidos fuera de España mediante gestación por sustitución, en el que afirmaba que: «en el estado legislativo y jurisprudencial actual, la instrucción de 5 de octubre de 2010, sobre régimen registral de la filiación de los nacidos mediante gestación por sustitución está plenamente vigente, por lo que debe seguir siendo aplicada por los Registros Civiles españoles a fin de determinar la inscribilidad del nacimiento y filiación en los casos que entran en su ámbito de aplicación, sin que la Sentencia de la Sala de lo Civil del Tribunal Supremo de 6 de febrero de 2014 constituya un obstáculo legal para ello». 
Así, la primera de las sentencias del Juez de Estrasburgo sobre la materia, de 26 de junio de 2014, en los asuntos Mennesson contra Francia y Labasse contra Francia, dirimía la negativa del Estado francés a inscribir la filiación de tres niñas nacidas por contrato de subrogación en el extranjero por contradecir el orden público $y$, en consecuencia, la legislación francesa vigente.

En los dos casos el supuesto de hecho es similar, y por ello el Tribunal de Estrasburgo resuelve en la misma sentencia. Dos matrimonios, los Mennesson y los Labasse, decidieron recurrir ante sus problemas de infertilidad a la maternidad subrogada en California y Minessota respectivamente, donde es legal, y el resultado fue el nacimiento de dos gemelas en el primer caso y de una niña en el segundo.

El Tribunal Supremo de ambos estados estadounidenses atribuyeron la paternidad legal de las niñas a los Mennesson y Labasse respectivamente con el consentimiento de todas las partes implicadas. Pero, las autoridades consulares francesas rehusaron inscribir a las niñas en el Registro civil por vulneración de la ley francesa, que prohíbe la maternidad subrogada — artículo 16.3 del Código Civil francés-. Después de un largo y complejo proceso judicial, la Corte de Casación francesa acabó rechazando definitivamente dicha inscripción por vulnerar el orden público.

Recurridas ambas sentencias ante el TEDH, sus argumentos son los siguientes:

En primer lugar, el Tribunal europeo analizó si se produjo violación del artículo 8 de la Convención Europea de Derechos Humanos, que reconoce el derecho a la vida privada personal y familiar ${ }^{24}$. Así, reconoció el amplio margen de apreciación de los Estados en lo relativo a la admisión de la maternidad subrogada y al reconocimiento de los vínculos de filiación entre los demandantes y los niños nacidos en el extranjero como consecuencia de esa técnica, debido a la falta de consenso europeo sobre tales cuestiones. Pero sostuvo que dicho margen debe ser reducido, matizado o relativizado cuando el problema se refiere a la filiación, en la medida en que ésta constituye un aspecto esencial de la identidad del niño.

Así, llegó a la conclusión de que el derecho de las menores a su vida privada, concretado en el derecho a su propia identidad, se había visto vulnerado por la imposibilidad de establecer vínculos jurídicos de filiación. Tal derecho, unido a la primacía del «interés del menor», determinaba que este último se viese vulnerado por la incertidumbre jurídica que producía no poder ser consideradas hijas

24 «1. Toda persona tiene derecho al respeto de su vida privada y familiar, de su domicilio y de su correspondencia». 2. No podrá haber injerencia de la autoridad pública en el ejercicio de este derecho sino en tanto en cuanto esta injerencia esté prevista por la ley y constituya una medida que, en una sociedad democrática, sea necesaria para la seguridad nacional, la seguridad pública, el bienestar económico del país, la defensa del orden y la prevención de las infracciones penales, la protección de la salud o de la moral, o la protección de los derechos y las libertades de los demás». 
de los recurrentes, a pesar de que uno de los miembros de las parejas era su padre biológico, siendo esto fundamental en la configuración de la identidad personal.

En palabras del Tribunal: «Cabe la posibilidad de que Francia pueda querer disuadir a sus nacionales de recurrir al extranjero para utilizar un método de procreación que prohíbe en su territorio (...) Sin embargo, se deduce de lo anterior, que los efectos de la falta de reconocimiento en la ley francesa de parentesco entre los hijos así concebidos y los padres intencionales no se limitan a la situación de estos últimos, que sólo han hecho la elección de la modalidad de procreación que le reprochan las autoridades francesas: también afectan a los propios niños, pues el respeto al derecho de la vida privada, que significa que todo el mundo puede establecer la sustancia de su identidad, incluyendo su filiación, se encuentra afectado significativamente. Esto plantea una cuestión grave de la compatibilidad de esta situación con el interés superior de los niños, pues el respeto debe regir toda decisión que les concierna». - Apartado 99 (Asunto Menesson) y apartado 78 (Asunto Labasse).

De modo que, a ojos del Tribunal de Estrasburgo, con la denegación del reconocimiento de efectos a las respectivas sentencias extranjeras, se impedía la condición de hijas a las menores nacidas por subrogación, lo cual implicaba que se veían privadas de los derechos inherentes a su identidad filial: incertidumbre en cuanto a la posibilidad de ver reconocida su nacionalidad francesa; limitación de sus derechos sucesorios; o, restricciones en la responsabilidad paterna. Ello suponía una vulneración de su interés superior que resultaba especialmente flagrante en la medida en que uno de los miembros de la pareja era el padre biológico.

En consecuencia, consideró el Juez de Estrasburgo que, no permitiéndose el reconocimiento de la filiación entre los padres intencionales y las niñas gestadas por subrogación por ningún medio - transcripción de actas de nacimiento, filiación biológica paterna, adopción o posesión de estado-, el Estado francés había ido más allá de lo que le permitía su margen de apreciación, ignorando el derecho de las niñas al respeto a su vida privada reconocido por el artículo 8 del Convenio.

En la Sentencia de 27 de enero de 2015, en el asunto Paradiso et Campanelli contra Italia, se dirimía un caso similar a los anteriores, a excepción de que en él ninguno de los recurrentes eran padres biológicos del niño nacido en Rusia futo de un contrato de maternidad subrogada. El Estado italiano se negó a inscribir en el Registro civil la filiación por ser este tipo de contratos contrarios al orden público.

Pero la Sala del TEDH sostuvo que el hecho de que el matrimonio hubiese pasado seis meses de convivencia con el menor, creaba unos vínculos familiares de facto cuya ruptura producía una clara vulneración de su interés superior. Y ello aunque no existiera vínculo genético alguno entre los demandantes y el hijo pues, según el Tribunal, el artículo 8 del Convenio protege no sólo la «vida familiar», sino también la «vida privada». 
Y, por lo que respecta a la invocación del orden público por parte del Estado italiano, el TEDH entendió que éste no era una carta blanca, sino que debía ser ponderado con el interés superior del menor con independencia de que existiese o no una relación genética con los padres intencionales identificado, en este caso, con la conveniencia de mantener al niño en su contexto familiar.

Sin embargo, Italia recurrió la Sentencia de la Sala y recientemente la Gran Sala del TEDH la ha revocado, acuñando una nueva e importantísima doctrina que implica un giro de ciento ochenta grados con respecto a la mantenida hasta entonces en materia de gestación por sustitución.

En su Sentencia de 24 de enero de 2017, la Gran Sala ha afirmado rotundamente que la retirada de la custodia del menor a los padres de intención no implica en modo alguno una vulneración del derecho a la vida privada y familiar consagrado en el artículo 8 del CEDH, por los siguientes motivos: entre el menor y los padres intencionales no existe relación biológica alguna, lo que diferencia a éste de los casos Menesson y Labasse contra Francia; porque no puede hablarse de vida familiar propiamente dicha al ser el periodo de convivencia entre los padres intencionales y el menor de tan solo 6 meses; porque no existe un derecho a ser padre o madre, sino que este es un mero deseo, pero lo que sí existe es un derecho del hijo a conocer su origen biológico; y, porque los padres de intención acudieron a la gestación por sustitución a Rusia a sabiendas de que en su país de origen, Italia, la misma está prohibida al vulnerar el orden público. Pero, quizás, el motivo más importante de entre los señalados por el Tribunal Europeo, consiste en afirmar que no puede establecerse la existencia de unos lazos familiares que deban ser protegidos por el Derecho cuando esos lazos se han constituido en violación de la ley. Por todo ello el TEDH concluye que debe prevalecer el orden público y la necesidad de garantizar el derecho de los menores a conocer su origen biológico sobre el deseo de ser padre/madre.

Se observa cómo, con esta Sentencia el Tribunal de Estrasburgo se posiciona, aunque no lo diga expresamente, con las posturas que consideran que la maternidad subrogada, además de vulnerar los derechos más fundamentales de las madres gestantes, atenta contra el interés de los menores que nacen bajo el paraguas de dicha práctica. Así pues, esperamos que España y el resto de los países miembros del Consejo de Europa, den traslado de su contenido no tanto a sus legislaciones que, como hemos visto, se adscriben mayoritariamente a este tipo de planteamientos, sino a una práctica administrativa atentatoria de su propia legislación interna.

\section{CONCLUSIONES}

El recurso a las llamadas «madres de alquiler» se ha convertido en un negocio mundial que mueve millones de euros al año. El hecho de que en España no esté permitida esta práctica no disuade a sus demandantes, que ven cómo con 
teclear el término «maternidad subrogada» en Google pueden acceder a múltiples opciones para llevarla a cabo en el extranjero, algo que sucede asimismo en los demás países europeos que prohíben la maternidad subrogada. Así, son innumerables las agencias que ofrecen libremente sus servicios en países donde la maternidad subrogada está permitida.

La «maternidad altruista» es un mito que legitima y encubre el auténtico negocio a nivel mundial — principalmente para los agentes intermediarios-que supone la comercialización del cuerpo de mujeres en clara situación de necesidad económica y social.

Esta práctica, que no es una técnica de reproducción asistida, vulnera muchos derechos y bienes jurídicos: así, se ha documentado el abandono de niños cuando la mujer gestante ha dado a luz a gemelos; cuando el número de fetos ha excedido del deseado por los contratantes; en el caso de que el niño nazca con algún tipo de enfermedad; o por el mero hecho de que el niño no resulte ser del sexo deseado por aquellos.

Por otro lado, han sido documentadas prácticas que indudablemente afectan a la dignidad y a la integridad física y moral de las madres gestantes, pues es común que las agencias que median en este tipo de contratos intenten atraer la demanda ofreciendo una amplia gama de posibilidades de elección para los contratantes relacionadas con las características de la gestante, el seguimiento del embarazo, la modalidad de parto y, por supuesto, las características del niño.

Por todo ello, la última e importante jurisprudencia del TEDH - coincidente con la del Tribunal Supremo español — tras llevar a cabo la preceptiva ponderación, ha llegado a la conclusión de que la maternidad subrogada vulnera aspectos esenciales de la dignidad humana y de la integridad física y moral de la madre gestante, así como derechos fundamentales del hijo nacido bajo este tipo de contratos, como su derecho a conocer su origen biológico.

$$
* * *
$$

TITLE: Surrogate Motherhood: a matter of fundamental rights.

ABSTRACT: In recent years we are immersed in a deep social, political and legal debate about the so-called surrogate motherhood. This practice, which consists of the implantation by in vitro fertilization or artificial insemination of an embryo in a mother, with which the parents of intention have signed a previous contract, with or without economic remuneration, implies a real conflict of fundamental rights. The present study intends, through the analysis of existing jurisprudence, to detect the rights of all the subjects involved and extract balancing parameters that guarantee the protection of those that must be prioritized, in order to guide the resolution of future cases and the design of policies in this area.

Resumen: En los últimos años nos encontramos inmersos en un profundo debate social, político y jurídico en torno a la llamada maternidad subrogada. Ésta, que consiste en la implantación por fecundación in vitro o inseminación artificial de un embrión en una madre gestante, con la que los padres de intención han firmado un contrato previo, con o sin remuneración económica, implica un auténtico conflicto de derechos fundamentales y bienes jurídicos. El presente estudio pretende, a través del análisis de la jurisprudencia existente, detectar los derechos de todos los sujetos implicados y extraer parámetros de ponderación que garanticen la 
protección de aquellos que deben priorizarse. Y ello con el fin de orientar la resolución de futuros casos y en el diseño de políticas en materia.

KEY WORDS: subrogated motherhood, dignity of the person, right to reproduction, right to autonomy, right to physical and moral integrity, higher interest of the minor.

PALABRAS ClAVE: maternidad subrogada, dignidad de la persona, derecho a la reproducción, derecho a la autonomía, derecho a la integridad física y moral, interés superior del menor.

FECHA DE RECEPCIÓN: 01.06.2018 FECHA DE ACEPTACIÓN: 05.02.2019 